\title{
Design of an Interacting Multiple Model-Cubature Kalman Filter Approach for Vehicle Sideslip Angle and Tire Forces Estimation
}

\author{
SuoJun Hou, ${ }^{1,2}$ Wenbo Xu, ${ }^{1}$ and Gang Liu $\mathbb{D}^{1}$ \\ ${ }^{1}$ College of Vehicle and Transportation Engineering, Henan Institute of Technology, XinXiang, China \\ ${ }^{2}$ State Key Laboratory of Automotive Simulation and Control, Jinlin University, Changchun 453000, China \\ Correspondence should be addressed to Gang Liu; gliu14@mails.jlu.edu.cn
}

Received 2 December 2018; Revised 14 April 2019; Accepted 2 May 2019; Published 20 June 2019

Academic Editor: Andras Szekrenyes

Copyright (C) 2019 SuoJun Hou et al. This is an open access article distributed under the Creative Commons Attribution License, which permits unrestricted use, distribution, and reproduction in any medium, provided the original work is properly cited.

\begin{abstract}
Vehicle states estimation (e.g., vehicle sideslip angle and tire force) is a key factor for vehicle stability control. However, the accurate values of these parameters could not be obtained directly. In this paper, an interacting multiple model-cubature Kalman filter (IMM-CKF) is used to estimate the vehicle state parameters. And improvements about estimation method are achieved in this paper. Firstly, the accuracy of the reference model is improved by building two different models: one is 7-degree-of-freedom (7 DOF) vehicle model with linear tire model, and the other is 7 DOF vehicle model with nonlinear Dugoff tire model. Secondly, the different models are switched by IMM-CKF to match different driving condition. Thirdly, the lateral acceleration correction for sideslip angle estimation is considered, because the sensor of lateral acceleration is easy to be influenced by the gravity on banked road. Then, to compare cubature Kalman filter (CKF) estimation method and IMM-CKF estimation method Hardware-In-Loop (HIL) tests are carried out in the paper. And simulation results show that IMM-CKF methodology can provide accurate estimation values of vehicle states parameters.
\end{abstract}

\section{Introduction}

With the development of the electronic and automotive technology, the vehicle stability control is also undergoing continuous progress. Vehicle stability control plays an important role in active vehicle safety control. The performance of vehicle stability control is determined by the accuracy of vehicle state (e.g., vehicle sideslip angle and tire force) because the vehicle state parameters show the potential of vehicle stability. However, the vehicle state parameters, such as the sideslip angle and tire force, cannot be measured directly for both technical and economic reasons. Therefore the vehicle state parameter must be estimated by a variety of algorithm methods.

Recently, many estimation approaches based on standard ESP sensors (e.g., steering angle, yaw rate, longitudinal and lateral acceleration, and wheel-speed) have been proposed in the literature to estimate vehicle state parameters [1]. These approaches can be divided into two types according to the vehicle dynamic models. Type 1 uses the linear vehicle model to estimate the sideslip angle and tire-road forces. Based on the linear vehicle model, known as the single-track model with a linear tire-force model, the estimation approach of vehicle state works well under normal driving condition [24] because the vehicle state depends on the tire force and the effect of tire force can change the trajectory of the vehicle. Figure 1 shows the relation between the tire force and the wheel slip angle. Under the normal driving condition, the value of wheel slip angle is small. Therefore the curve, which reflects the relationship between the tire force and the wheel slip angle, is initially linear. Many algorithms, such as the variable forgetting factor recursive least squares algorithm [5], Luenberger linear Observer [6], $H_{\infty}$ filtering [7], and Kalman filters $[8,9]$, based on the linear model have been used to estimate the vehicle state parameters. However, the vehicle cannot always be under normal driving condition. Under extreme driving conditions, the value of vehicle state tends to nonlinear growth. Figure 1 shows that, as the wheel slip angle grows, the tire force gradually enters into the nonlinear region, which is caused by the limited friction on 


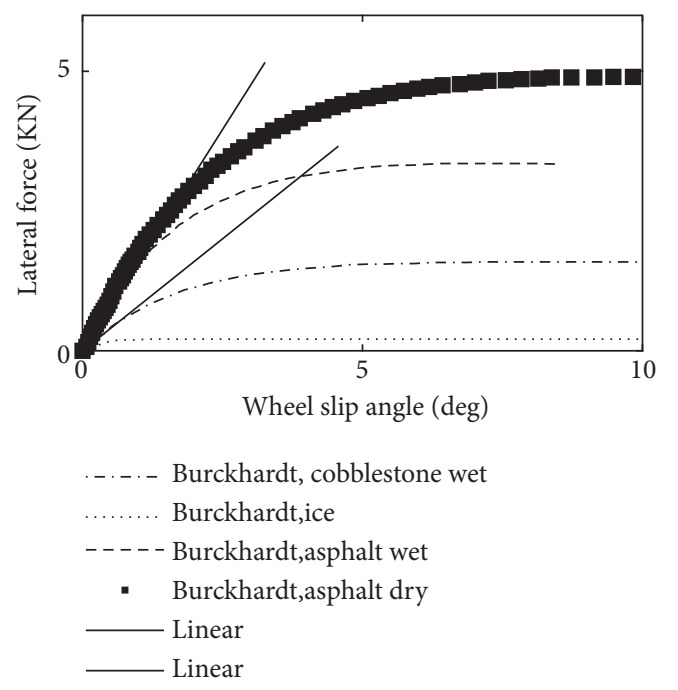

FIGURE 1: Lateral force curve.

the road surface, especially on a low friction road. Consequently, the parameters estimated based on linear vehicle model are error due to the tire's inherent nature. Compared to type 1, type 2 uses the estimation approach based on the nonlinear vehicle model $[10,11]$, which is more close to reflect the vehicle dynamics nature, to predict the vehicle state under extreme driving conditions. A lot of literatures have been proposed to estimate the parameters based on the nonlinear vehicle model. Liang Li and Gang Jia proposed a variable structure extended Kalman filter with the sideslip angle rate feedback to estimate the sideslip angle [12]. Their simulations and vehicle winter test show that the proposed approach can provide accurate value of sideslip under low friction road conditions. Yu and Kh Guo proposed a reducedorder sliding mode observer for vehicle state estimation [13, 14]. The precise nonlinear tire model "UniTire" is used to improve the accuracy of vehicle states parameters estimation. A novel approach is proposed to estimate parameters by using a mathematical tool, which includes a nonlinear Magic tire model [15]. B.L.Boada proposed a novel observer based on adaptive Neuro-Fuzzy Inference System (ANFIS), combined with Unscented Kalman Filter in order to estimate the sideslip angle and tire force [16]. Wei L. proposed an estimation approach based on the Extended Kalman Filter (EKF) combing with the Minimum Model Error (MME) criterion for vehicle state estimation [17]. However, the estimation based on nonlinear vehicle model is not suitable for parameters estimations under normal driving conditions because of the excessive computational power in embedded systems. In sum, the time to choose an optimal model for various driving conditions is also important besides the choice of vehicle model. The multiple model (MM) method takes advantage of several models to express possible vehicle model under different driving conditions, which can achieve more accurate vehicle state parameters by combined filters based on corresponding vehicle model of a limited number of different models compared with single vehicle model. Among several MM estimation algorithms, the interacting

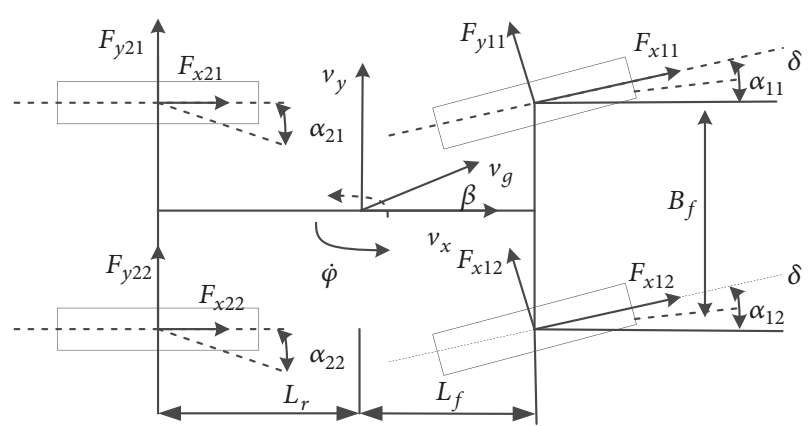

Figure 2: 7-DOF vehicle model.

MM (IMM) has attracted wide attention because it can obtain accurate calculation results with low computational load [18].

In this paper, we use the interacting multiple model (IMM) to choose an optimal model for various driving conditions. In the IMM method, two filters are used in parallel to estimate sideslip angle and tire force. One filter is CKF filter based on four-wheel nonlinear vehicle dynamics model with linear tire model for normal driving conditions and the other is based on four-wheel nonlinear vehicle dynamics model with nonlinear Dugoff tire model for extreme driving conditions. The sideslip angle and tire force predicted by the variable structure IMM-CKF filter are more accurate than the single filter for various driving conditions.

This paper is organized as follows. In Section 2, the dynamics models of the vehicle, linear tire, and nonlinear Dugoff tire model are presented, respectively. In Section 3, the detailed structure of IMM-CKF is represented. In Section 4, the key dynamics variable is given in detail. In Section 5 the simulations are presented to validate the performance of the estimation method.

\section{Design of Vehicle Dynamics Model}

2.1. Vehicle Model. In Figure 2, the 7-DOF vehicle dynamics model is proposed to estimate the vehicle state parameters. The 7-DOF vehicle model includes longitudinal motion, lateral motion, yaw motion, and 4-wheel rotation [13].

The equation of longitudinal motion is expressed as follows:

$$
\begin{aligned}
m\left(\dot{v}_{x}-v_{y} \dot{\varphi}\right)= & \sum_{i, j=1}^{2} F_{x i j} \\
= & \left(F_{x 11}+F_{x 12}\right) \cos \delta+\left(F_{x 21}+F_{x 22}\right) \\
& -\left(F_{x 11}+F_{x 12}\right) \sin \delta=m a_{x}
\end{aligned}
$$

The equation of lateral motion is expressed as follows:

$$
\begin{aligned}
m\left(\dot{v}_{y}+v_{x} \dot{\varphi}\right)= & \sum_{i, j=1}^{2} F_{y i j} \\
= & \left(F_{y 11}+F_{y 12}\right) \cos \delta+\left(F_{y 21}+F_{y 22}\right) \\
& -\left(F_{y 11}+F_{y 12}\right) \sin \delta=m a_{y}
\end{aligned}
$$


The equation of yaw motion is expressed as follows:

$$
\begin{aligned}
I_{z} \ddot{\varphi}= & \left(F_{y 11}+F_{y 12}\right) L_{f} \cos \delta+\left(F_{y 11}-F_{y 12}\right) L_{r} \sin \delta \\
& -\left(F_{y 21}+F_{y 22}\right) L_{r}-\left(F_{x 11}-F_{x 12}\right) L_{f} \sin \delta \\
& -\left(F_{x 11}-F_{x 12}\right) \frac{B_{f}}{2} \cos \delta-\left(F_{x 21}-F_{x 22}\right) \frac{B_{f}}{2}
\end{aligned}
$$

The equation of wheel motion is expressed as follows:

$$
J_{w} \dot{w}_{i j}=T_{i j}-p_{i j} K_{P T i j}-F_{x i j} R
$$

The equation about sideslip angle can be expressed as follows:

$$
\begin{aligned}
m(\dot{\beta}+\dot{\varphi}) v_{g}= & \left(F_{y 11}+F_{y 12}\right) \cos (\beta-\delta) \\
& +\left(F_{y 11}+F_{y 12}\right) \cos \beta \\
& -\left(F_{x 11}+F_{x 12}\right) \sin (\beta-\delta) \\
& -\left(F_{x 11}+F_{x 12}\right) \sin \beta \\
m \dot{v}_{g}= & \left(F_{x 11}+F_{x 12}\right) \cos (\beta-\delta) \\
& +\left(F_{x 21}+F_{x 22}\right) \cos \beta \\
& +\left(F_{y 11}+F_{y 12}\right) \sin (\beta-\delta) \\
& +\left(F_{y 11}+F_{y 12}\right) \sin \beta
\end{aligned}
$$

where $\mathrm{m}$ represents the mass of the vehicle; $\beta$ denotes the sideslip angle; $\delta$ denotes the front steering angle; $v_{x}$ represents the longitudinal velocity; $v_{y}$ is the lateral velocity of the vehicle; $F_{x i j}$ denotes the longitudinal tire force of 4 wheels, respectively; $F_{y i j}$ denotes the lateral tire force of 4 wheels, respectively; $L_{f}$ and $L_{r}$ are the distances from the front and rear axle to the gravity center, respectively; $B_{f}$ represents track width of the vehicle; $J_{w}$ denotes the wheel inertia; $T_{i j}$ denotes driving torque; $p_{i j}$ denotes the brake pressure of wheels; $K_{P T i j}$ denotes the coefficient of the brake pressure; $\omega_{i j}$ denotes the speed of 4 wheels, respectively; $I_{z}$ is the yaw moment of inertia. $\mathrm{R}$ is the wheel radius; $\varphi$ is yaw angle.

2.2. Tire Model. When the vehicle is turning, the longitudinal acceleration and the later acceleration will have an effect on each wheel because of the load transfer. Therefore, the vertical load of 4 wheels can be expressed as follows:

$$
\begin{aligned}
& F_{z 11}=\frac{m g L_{r}}{2 L}-\frac{m h_{c g} a_{x}}{2 L}-\frac{h_{c g} L_{r}}{L B_{f}} m a_{y} \\
& F_{z 12}=\frac{m g L_{r}}{2 L}+\frac{m h_{c g} a_{x}}{2 L}+\frac{h_{c g} L_{f}}{L B_{f}} m a_{y} \\
& F_{z 21}=\frac{m g L_{f}}{2 L}+\frac{m h_{c g} a_{x}}{2 L}+\frac{h_{c g} L_{f}}{L B_{f}} m a_{y} \\
& F_{z 22}=\frac{m g L_{r}}{2 L}+\frac{m h_{c g} a_{x}}{2 L}-\frac{h_{c g} L_{f}}{L B_{f}} m a_{y}
\end{aligned}
$$

where $F_{z i j}$ denotes the vertical force of 4 wheels; $h_{c g}$ denotes the distance between the gravity center and the ground; $a_{y}$ denotes the lateral acceleration; $a_{x}$ denotes the longitude acceleration; $\mathrm{L}$ denotes the distances between the front axle and rear axles.

As discussed in Section 1, in case of vehicle driving under normal driving conditions, the relationship between the lateral force and the tire slip angle is linear. On the other hand, under extreme driving conditions, the lateral acceleration of vehicle tends to be big, and the tire operates in the nonlinear region. Therefore, in this paper, linear tire model and the nonlinear tire model are established.

2.2.1. Linear Tire Model. The linear tire model proposed by the authors [19] is adopted in this paper. The tire slip angles can be formulated as follows:

$$
\left[\begin{array}{l}
\alpha_{11} \\
\alpha_{12} \\
\alpha_{21} \\
\alpha_{22}
\end{array}\right]=\left[\begin{array}{l}
\delta \\
\delta \\
0 \\
0
\end{array}\right]-\left[\begin{array}{l}
\xi_{11} \\
\xi_{12} \\
\xi_{21} \\
\xi_{22}
\end{array}\right]
$$

where $\xi_{i j}$ can be expressed as

$$
\left[\begin{array}{l}
\xi_{11} \\
\xi_{12} \\
\xi_{21} \\
\xi_{22}
\end{array}\right]=\tan ^{-1}\left[\begin{array}{c}
\frac{v_{y}+L_{f} \dot{\varphi}}{v_{x}-B_{f} \dot{\varphi} / 2} \\
\frac{v_{y}+L_{f} \dot{\varphi}}{v_{x}+B_{f} \dot{\varphi} / 2} \\
\frac{v_{y}-L_{r} \dot{\varphi}}{v_{x}-B_{r} \dot{\varphi} / 2} \\
\frac{v_{y}-L_{r} \dot{\varphi}}{v_{x}+B_{r} \dot{\varphi} / 2}
\end{array}\right] \approx\left[\begin{array}{c}
\frac{v_{y}+L_{f} \dot{\varphi}}{v_{x}-B_{f} \dot{\varphi} / 2} \\
\frac{v_{y}+L_{f} \dot{\varphi}}{v_{x}+B_{f} \dot{\varphi} / 2} \\
\frac{v_{y}-L_{r} \dot{\varphi}}{v_{x}-B_{r} \dot{\varphi} / 2} \\
\frac{v_{y}-L_{r} \dot{\varphi}}{v_{x}+B_{r} \dot{\varphi} / 2}
\end{array}\right]
$$

At small slip angle, the lateral tire force is proportion to the tire slip angle. The equation of lateral tire force can be written as follows:

$$
F_{y i j}=-C_{y i j} \alpha_{i j}
$$

where $C_{y i j}$ represents cornering stiffness of 4 wheels, respectively.

The equation of longitudinal tire force can be expressed as

$$
F_{x i j}=k_{\mu} \lambda_{i j} F_{z i j}
$$

where $\lambda_{i j}$ denotes the slip ratio of 4 wheels, respectively; $k_{\mu}$ is the proportional coefficient.

2.2.2. Nonlinear Tire Model. Under the extreme driving conditions, such as a low friction road surface, the tire is easy to enter into nonlinear state even at low lateral acceleration. Thus, the Dugoff nonlinear tire model is used to represent the tire forces in nonlinear region [20].

The equations of lateral tire force and the longitudinal tire forces can be expressed as

$$
\begin{aligned}
& F_{y i j}=\frac{C_{y i j} \tan \alpha_{i j}}{1-\lambda_{i j}} f(S) \\
& F_{x i j}=\frac{C_{x i j} \lambda_{i j}}{1-\lambda_{i j}} f(S)
\end{aligned}
$$




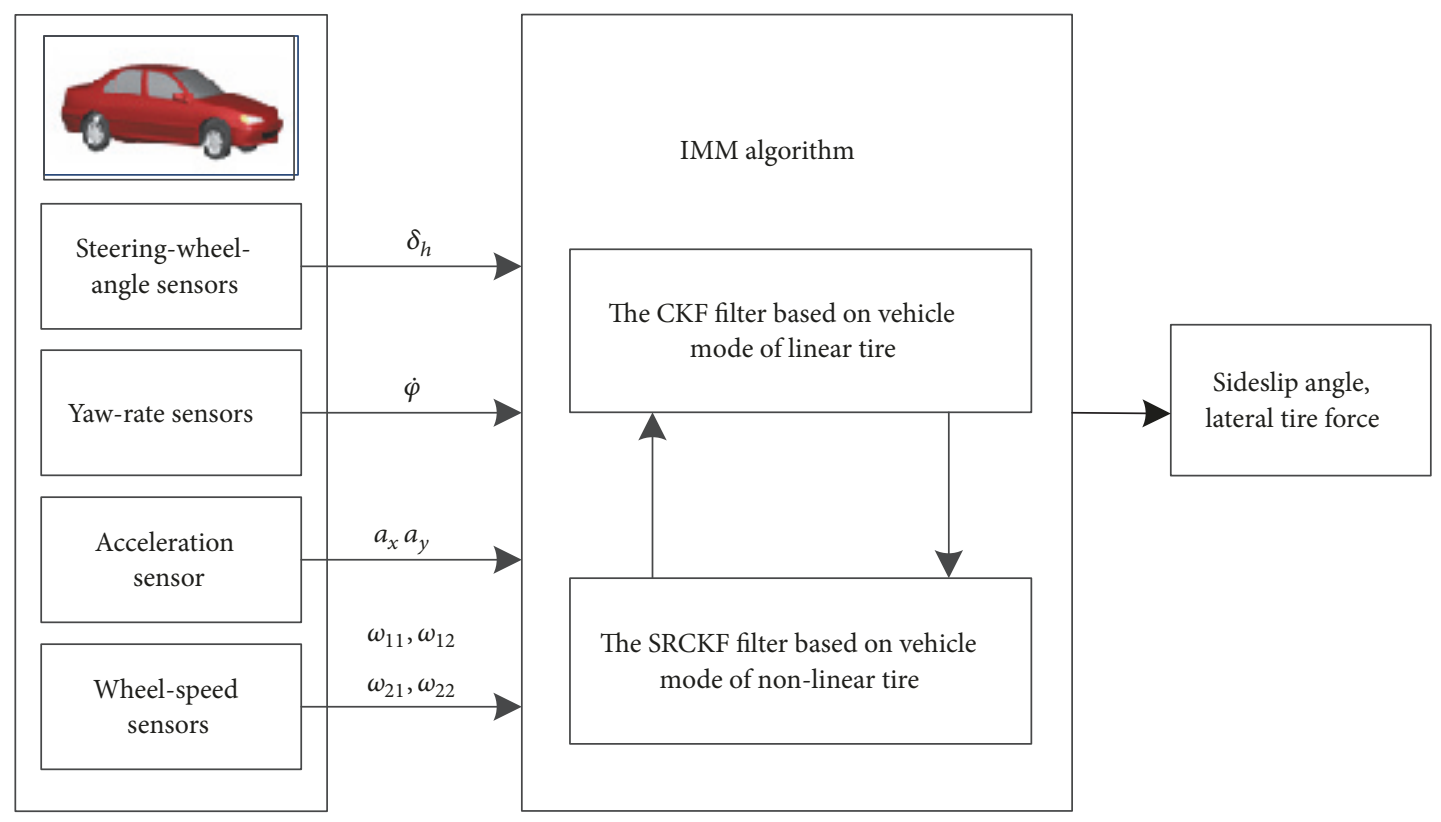

FIGURE 3: Scheme of the IMM-CKF method for vehicle state estimation.

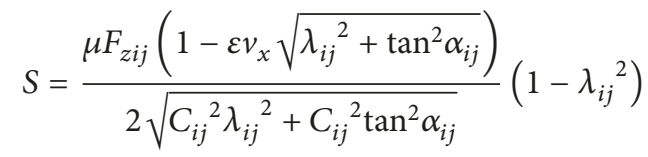

$$
\begin{aligned}
& f(S)= \begin{cases}1 & S>1 \\
S(2-S) & S<1\end{cases} \\
& \lambda_{i j}=\frac{R_{w} \omega_{i j}-v_{x}}{\max \left(R_{w} \omega_{i j}, v_{x}\right)}
\end{aligned}
$$

where $\varepsilon$ denotes roll steer coefficient.

2.2.3. Modified Tire-Road Force. Considering the time lag of tire force, Reference [21] proposed a relaxation length to represent the transient behavior of tires. The modified tireroad force can be expressed as

$$
\begin{aligned}
& \dot{F}_{y i j}=\frac{v_{g}}{\sigma_{i j}}\left(-F_{y i j}+\bar{F}_{y i j}\right) \\
& \dot{F}_{x i j}=\frac{v_{g}}{\sigma_{i j}}\left(-F_{x i j}+\bar{F}_{x i j}\right)
\end{aligned}
$$

where $\bar{F}_{y i j}$ denotes the quasi-static lateral Dugoff tire force; $\sigma_{i j}$ denotes the relaxation coefficient.

\section{IMM-CKF}

The algorithm structure of vehicle state estimation proposed in this paper is shown in Figure 3. The whole algorithm structure can be regarded as hierarchical strategy, and it can be divided into 2 layers. The first layer is signal layer. In the first layer, the signals obtained by the sensors or derived from other systems are transmitted to next layers for estimation, and these signals include the longitudinal acceleration $a_{x}$, the lateral acceleration $a_{x}$, yaw rate $\dot{\varphi}$, longitudinal speed $v_{x}$, speed of each $\omega_{i j}$, steer angle $\delta_{h}$, and break pressure of each wheel cylinder $p_{i j}$. The second layer is responsible for calculation of weight according to the road friction coefficient and vehicle lateral acceleration.

In the second layer, the IMM-based estimation layer calculates the model switch probabilities and integrates the CKF estimation of each model by stochastic process to adapt to various driving conditions. The further algorithm about IMM-CKF can be found in Reference [22].

It is appropriate that the filter of 7-DOF vehicle model based on linear tire model is used under the normal work conditions because the relationship of tire slip angle and lateral force is linear and there is a small amount of computations for embedded system. In contrast, the relationship of the tire slip angle and the lateral force is no longer linear under extreme driving conditions. The filter of 7-DOF vehicle model based on nonlinear tire model can provide better prediction performance. The process of IMM-CKF can be described in Figure 4. The IMM-CKF can be broken down into 4 steps:

Step 1 (interaction reinitialization). Compute the mixed probabilities and the initial condition in first step. Initial mean and covariance for each CKF filter model can be expressed as follows:

$$
\begin{aligned}
& \bar{x}_{k-1 \mid k-1}^{(i)}=E\left(x_{k-1} \mid m_{k}^{(i)} Z^{k-1}\right)=\sum_{i=1}^{r} \widehat{x}_{k-1 \mid k-1}^{(i)} \mu_{k-1 \mid k-1}^{(i, j)} \\
& \bar{p}_{k-1 \mid k-1}^{(i)}=\sum_{i=1}^{r}\left[P_{k-1 \mid k-1}^{(i)}\right. \\
& \left.+\left(\widehat{x}_{k-1 \mid k-1}^{(j)}-\bar{x}_{k-1 \mid k-1}^{(j)}\right)\left(\widehat{x}_{k-1 \mid k-1}^{(j)}-\bar{x}_{k-1 \mid k-1}^{(j)}\right)^{T}\right] \\
& \cdot \mu_{k-1 \mid k-1}^{(i, j)}
\end{aligned}
$$




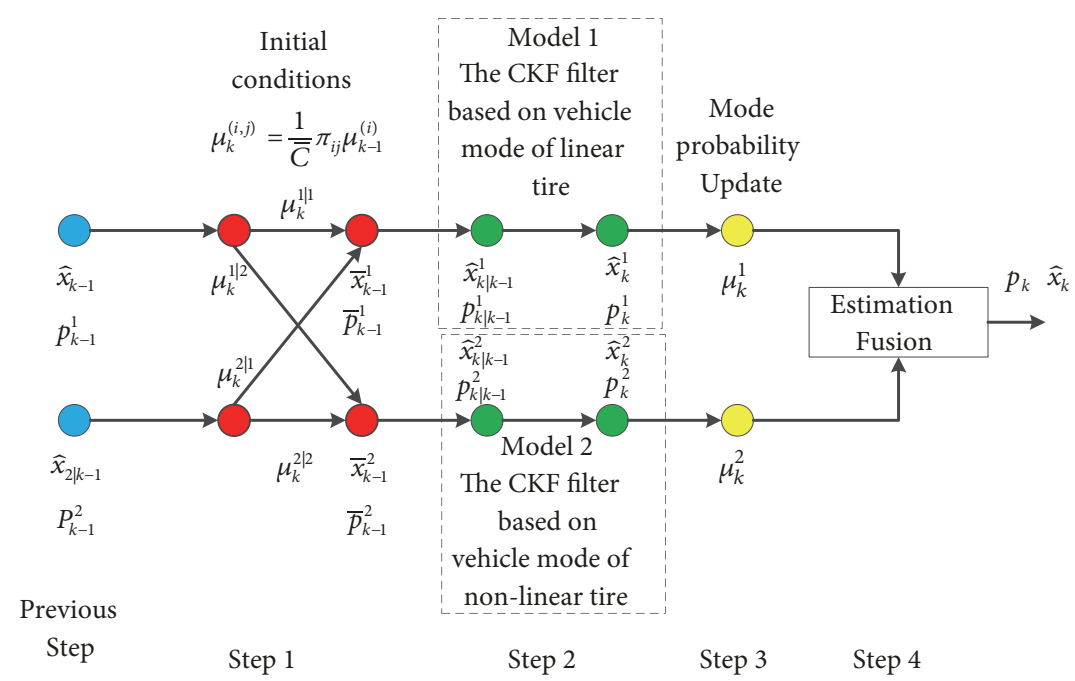

FIgURE 4: The process of IMM-CKF.

where $\mu_{k-1 \mid k-1}^{(i, j)}=P\left(m_{k-1}^{(i)} \mid m_{k}^{(i)} Z^{k-1}\right)=(1 / \bar{C}) \pi_{i j} \mu_{k-1}^{(i)} i, j=$ $1,2, \ldots, r$.

$\mu_{k-1 \mid k-1}^{(i, j)}$ is mixing probabilities of model $i$; the model switch probabilities of the IMM filter between the two models are due to the Markov Process, which is determined by the transition probability matrix $\pi_{i j}$. The model transition probability matrix $\pi_{i j}$ denotes the transition probability of vehicle model from model $j$ to model $i$. The parameter $\pi_{i j}$ can be expressed as

$$
\pi_{i j}=\left[\begin{array}{ll}
0.99 & 0.01 \\
0.02 & 0.98
\end{array}\right]
$$

where $j, i$ denote the 7-DOF vehicle model with linear tire model and 7-DOF vehicle model with nonlinear Dugoff tire model, respectively. These values of model switch probability matrix were obtained by a statistical method, which related to the sampling time interval under the real driving condition [23-26].

Step 2 (mode-filtering using CKF and then computation of the model probability update). In this step, the CKF is used to obtain each model state $\widehat{x}_{k \mid k}$ and covariance $P_{k \mid k}$ which is based on the previous mixing state $\bar{x}_{k-1 \mid k-1}^{(i)}$ and the covariance $\bar{p}_{k-1 \mid k-1}^{(i)}$. The overall flowchart of the CKF for vehicle model $i$ is presented in Figure 5. The state equation of the vehicle model with the linear tire model is similar to that of the vehicle model with nonlinear Dugoff tire model. The state equation of the vehicle model with the linear tire model includes equations (1), (2), (3), (4), (5), (6), (9), (10), and (11). The state equation of the vehicle model with nonlinear Dugoff tire model includes equations (1), (2), (3), (4), (5), (6), (9), (12), and (13). Both state equations can be expressed as

$$
\begin{aligned}
& \dot{x}(t)=f(x(t), u(t))+W(t) \\
& y(t)=h(x(t), u(t))+V(t)
\end{aligned}
$$

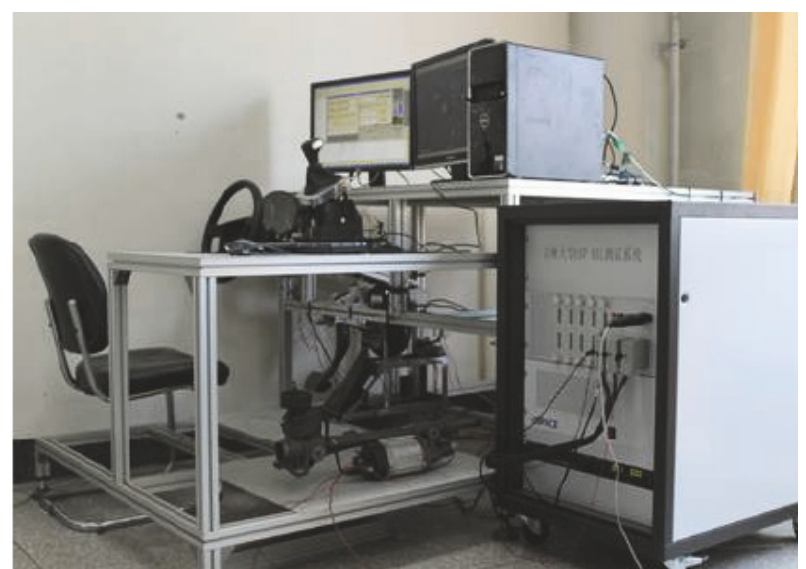

FIGURE 5: HIL simulation platform.

The input vector of both models can be written as

$$
u=\left[\delta_{h}, \omega_{11}, \omega_{12}, \omega_{21}, \omega_{22}\right]
$$

The output of both models can be described as

$$
y=\left[a_{x}, a_{y}, \dot{\varphi}, \omega_{11}, \omega_{12}, \omega_{21}, \omega_{22}\right]
$$

The state of both models can be expressed as

$$
x=\left[\dot{\varphi}, v_{g}, \beta, F_{y 11}, F_{y 12}, F_{y 21}, F_{y 22}, F_{x 11}, F_{x 12}, F_{x 21}, F_{y 22}\right]
$$

Hence, the function $f($.$) of equation (17) can be written as$

$$
\begin{aligned}
f_{1} & =\frac{1}{I_{z}}\left[\left(x_{4}+x_{5}\right) L_{f} \cos u_{1}+\left(x_{4}-x_{5}\right) L_{r} \sin u_{1}\right. \\
& -\left(x_{6}+x_{7}\right) L_{r}-\left(x_{8}-x_{9}\right) L_{f} \sin u_{1} \\
& \left.-\left(x_{8}-x_{9}\right) \frac{B_{f}}{2} \cos u_{1}-\left(x_{10}-x_{11}\right) \frac{B_{f}}{2}\right]
\end{aligned}
$$




$$
\begin{aligned}
f_{2} & =\frac{1}{m}\left[\left(\left(x_{8}+x_{9}\right) \cos \left(x_{3}-u_{1}\right)+\left(x_{6}+x_{7}\right) \cos x_{3}\right.\right. \\
& \left.+\left(x_{4}+x_{5}\right) \sin \left(x_{3}-u_{1}\right)+\left(x_{4}+x_{5}\right) \sin x_{3}\right] \\
f_{3} & =\frac{1}{m x_{2}}\left[\left(x_{4}+x_{5}\right) \cos \left(x_{3}-u_{1}\right)+\left(x_{4}+x_{5}\right) \cos x_{3}\right. \\
& \left.-\left(x_{8}+x_{9}\right) \sin \left(x_{3}-u_{1}\right)-\left(x_{8}+x_{9}\right) \sin x_{3}\right]-x_{1} \\
f_{4} & =\frac{x_{2}}{\sigma_{11}}\left(-x_{4}+\bar{F}_{y 11}\right), \\
f_{5} & =\frac{x_{2}}{\sigma_{12}}\left(-x_{5}+\bar{F}_{y 12}\right), \\
f_{6} & =\frac{x_{2}}{\sigma_{21}}\left(-x_{6}+\bar{F}_{y 21}\right) \\
f_{7} & =\frac{x_{2}}{\sigma_{22}}\left(-x_{7}+\bar{F}_{y 22}\right), \\
f_{8} & =\frac{x_{2}}{\sigma_{11}}\left(-x_{8}+\bar{F}_{x 11}\right), \\
f_{11} & =\frac{x_{2}}{\sigma_{22}}\left(-x_{11}+\bar{F}_{x 22}\right) \\
f_{10} & =\frac{x_{2}}{\sigma_{21}}\left(-x_{10}+\bar{F}_{x 12}\right) \\
\left.f_{21}\right), &
\end{aligned}
$$

The measurement function $\mathrm{h}($.$) of equation (21) can be$ written as

$$
\begin{aligned}
h_{1} & =\frac{1}{m}\left[\left(x_{8}+x_{9}\right) \cos u_{1}+x_{6}+x_{7}\right. \\
& \left.-\left(x_{8}+x_{9}\right) \sin u_{1}\right] \\
h_{2} & =\frac{1}{m}\left[\left(x_{4}+x_{5}\right) \cos u_{1}+x_{10}+x_{11}\right. \\
& \left.-\left(x_{4}+x_{5}\right) \sin u_{1}\right] \\
h_{3} & =x_{1}, \\
h_{4} & =u_{2}, \\
h_{5} & =u_{3}, \\
h_{6} & =u_{4}, \\
h_{7} & =u_{5}
\end{aligned}
$$

Before using the CKF to estimate the state vector $x(t)$, equation (21) should be discretized as follows:

$$
\begin{aligned}
& x_{k}=f\left(x_{k-1}, u_{k-1}\right)+w_{k-1} \\
& z_{k}=h\left(x_{k}, u_{k}\right)+v_{k}
\end{aligned}
$$

where $x_{k} \in \mathfrak{R}^{n_{x}}$ denotes the state of the vehicle system at discrete time k; $z_{k} \in \mathfrak{R}^{n_{x}}$ denotes measurement; $u_{k} \in \mathfrak{R}^{n_{x}}$ denotes the input; $w_{k-1} \in \mathfrak{R}^{n_{x}}$ and $v_{k} \in \mathfrak{R}^{n_{x}}$ denote independent process and measurement Gaussian noise sequences assumed to be in white independent and with covariance $Q_{k}$ and $R_{k}$, respectively. The CKF can be expressed as follows:

(i) Time Update

$$
\begin{aligned}
S_{k-1 \mid k-1} & =\operatorname{SVD}\left(P_{k-1 \mid k-1}\right) \\
\chi_{k-1 \mid k-1} & =S_{k-1 \mid k-1} \xi+x_{k-1 \mid k-1} \\
\chi_{k \mid k-1}^{*} & =f\left(\chi_{k-1 \mid k-1}\right) \\
x_{k \mid k-1} & =\frac{1}{m} \sum_{i=1}^{m} \chi_{i, k \mid k-1}^{*} \\
P_{k \mid k-1} & =\frac{1}{m} \sum_{i=1}^{m} \chi_{i, k \mid k-1}^{*} \chi_{i, k \mid k-1}^{* T}-x_{k \mid k-1} x_{k \mid k-1}^{T}+Q_{k}
\end{aligned}
$$

(ii) Measurement Update

$$
\begin{aligned}
S_{k \mid k-1} & =\operatorname{SVD}\left(P_{k \mid k-1}\right) \\
\chi_{k \mid k-1} & =S_{k \mid k-1} \xi+x_{k \mid k-1} \\
Z_{k \mid k-1} & =h\left(\chi_{k \mid k-1}\right) \\
z_{k \mid k-1} & =\frac{1}{m} \sum_{i=1}^{m} Z_{i, k \mid k-1} \\
P_{z z, k \mid k-1} & =\frac{1}{m} \sum_{i=1}^{m} Z_{i, k \mid k-1} Z_{i, k \mid k-1}^{T}-z_{k \mid k-1} z_{k \mid k-1}^{T}+R_{k} \\
P_{x z, k \mid k-1} & =\frac{1}{m} \sum_{i=1}^{m} \chi_{i, k \mid k-1} Z_{i, k \mid k-1}^{T}-x_{k \mid k-1} z_{k \mid k-1}^{T}+R_{k} \\
K_{k} & =P_{x z, k \mid k-1} P_{z z, k \mid k-1}^{-1} \\
x_{k \mid k} & =x_{k \mid k-1}+K_{k}\left(z_{k}-z_{k \mid k-1}\right) \\
P_{k \mid k} & =P_{k \mid k-1}-K_{k} P_{z z, k \mid k-1} K_{k}^{T}
\end{aligned}
$$

where SVD denotes the matrix singular value decomposition method; $S$ represents the square-root of the covariance matrix $\mathrm{P} ; \mathrm{m}=2 \mathrm{n}, \mathrm{m}$ denotes the total number of Cubature points; $\xi=$ $\sqrt{m / 2}[1]_{i} ; \chi_{i}$ is the Cubature point which is generated by the states equations; $Z_{i}$ is the Cubature point which is generated by measurements.

Step 3 (model probability update). In this step, the likelihood function of each mode can be expressed as

$$
\begin{aligned}
\Lambda_{k}^{(i)} & =P\left(\widetilde{z}_{k}^{(i)} \mid m_{k}^{(i)}, z^{k-1}\right) \\
& =\left|2 \pi S_{k}^{(i)}\right|^{-1 / 2} \exp \left\{-\frac{1}{2}\left(\widetilde{z}_{k}^{(i)}\right)^{T}\left(S_{k}^{(i)}\right)^{-1} \widetilde{z}_{k}^{(i)}\right\} \\
\mu_{k}^{(i)} & =P\left(m_{k}^{(i)} \mid z^{k}\right)=\frac{1}{c} \Lambda_{k}^{(i)} \bar{c}_{j} \\
c & =\sum_{i=1}^{r} \Lambda_{k}^{(i)} \bar{c}_{j}
\end{aligned}
$$


where $S_{k}^{(i)}=H_{k}^{(i)} P_{k \mid k-1}^{(i)}\left(H_{k}^{(i)}\right)^{T}+R_{k}^{(i)} ; S_{k}^{(i)}$ denotes the innovation covariance. $c$ denotes the normalization factor.

Step 4 (estimation fusion). After calculation of each mode's probabilities, the vehicle state parameters prediction and the covariance can be calculated according to Gaussian mixture equation. The equation of vehicle state parameters prediction and its covariance can be, respectively, expressed as

$$
\begin{aligned}
& \widehat{x}_{k \mid k}=\sum_{i=1}^{r} \widehat{x}_{k}^{(i)} \mu_{k}^{(i)} \\
& P_{k \mid k}=\sum_{i=1}^{r}\left[P_{k \mid k}^{(i)}+\left(\widehat{x}_{k \mid k}-\widehat{x}_{k \mid k}^{(i)}\right)\left(\widehat{x}_{k \mid k}-\widehat{x}_{k \mid k}^{(i)}\right)^{T}\right] \mu_{k}^{(i)}
\end{aligned}
$$

\section{Key Dynamics Variable of VSIMM-CKF}

The sensor of lateral acceleration is a sort of inertial sensors which is easily affected by the gravity when the axis of chassis is not horizontal. Therefore, the outputs of lateral acceleration sensor need to be corrected. Similarly, road adhesion coefficient and cornering stiffness correction are very important, so they are introduced separately in this section.

4.1. Correction of Lateral Acceleration. In case of vehicle driving on the flat and level road, the measured results of lateral acceleration are precise. But in case of driving on the slope road, the measured results tend to become higher than those on the flat and level road. Because the lateral acceleration sensor is easy to be influenced by the roll angle of the vehicle, therefore, it is necessary to correct the measured results before being used in the vehicle state estimation. The equation of correct lateral acceleration can be written as

$$
a_{y}=a_{y m}-g \alpha_{\text {roll }}
$$

where $a_{y}$ denotes the corrected lateral acceleration; $\alpha_{\text {roll }}$ denotes the roll angle; $a_{y m}$ denotes the measured results of lateral acceleration.

The equation of roll angle can be expressed as

$$
\alpha_{\text {roll }}=\frac{m a_{y} h_{\text {roll }}}{K_{F}+K_{R}-m g h_{\text {roll }}}
$$

where $h_{\text {roll }}$ denotes the distance between the gravity and the axis of rolling; $K_{F}$ denotes the rolling stiffness of front suspension; $K_{R}$ denotes the rolling stiffness of rear suspension.

4.2. Road Friction Estimation. Road friction plays an important role in vehicle state estimation. However, it is difficult to acquire its value directly. According to the estimation method proposed in Reference [27], the value of road friction can be calculated as follows:

$$
\mu=\left|\frac{a_{y}}{g}\right|+\mu_{e}
$$

where $g$ denotes the gravitational acceleration; $\mu_{e}$ denotes the evaluated error. The value of $\mu_{e}$ can be referred in Reference [27].
4.3. Correction of Cornering Stiffness. According to Reference [27], the cornering stiffness can be expressed as a second order polynomial of tire force. But in the real vehicle dynamics system, the lateral tire force is always coupled with the longitudinal tire force. In order to minimize the discrepancy caused by simplification, the following correction is applied to cornering stiffness. According to Reference [28], Pacejka and H.B. proposed the limiting factor with the longitudinal tire force as input variable for the condition where no longitudinal dynamics is considered:

$$
\varphi_{l f}=\frac{\sqrt{\mu^{2} F_{z i j}^{2}-F_{x i j}^{2}}}{\mu F_{z i j}}
$$

The limiting factor limits the max lateral tire force to its certain fraction, which conversely redefines the cornering stiffness as follows:

$$
\begin{aligned}
C_{\alpha}( & \left.\mu, F_{z i j}, F_{x i j}\right) \\
= & \varphi_{l f}\left\{C_{\alpha}\left(\mu, F_{z i j}, F_{x i j}=0\right)-\frac{1}{2} \mu F_{z i j}\right\} \\
& +\frac{1}{2}\left(\mu F_{z i j}-F_{x i j}\right)
\end{aligned}
$$

\section{Simulation Verification}

In order to validate the proposed estimation method, the simulations were carried out. The simulations are based on the Hardware-In-Loop (HIL) and the simulation platform is shown in Figure 5. Vedyna [29] is used to describe the vehicle model, and the vehicle model is downloaded into the Simulator of DSPACE. The vehicle state estimation algorithm is realized by Matlab/Simulink, and the method is also downloaded into the MicroAutobox of DSPACE. The signal of steering angle, which is generated by driver, is transmitted to the Simulator. And then the vehicle state is changed by the operation of the driver. The MicroAutobox receives the signal of vehicle state such as the longitudinal acceleration $a_{x}$, the lateral acceleration $a_{y}$, the yaw rate $\dot{\varphi}$, the steering angle $\delta$, and the wheels speed $\omega_{i j}$ by CAN BUS the Simulator. In order to improve CANBUS delay problem, a node is selected as the synchronization node. The synchronization node sends a synchronization message with ID0 once every $300 \mathrm{~ms}$ interval. The transmission intervals of other nodes are set to $5 \mathrm{~ms}, 10 \mathrm{~ms}, 20 \mathrm{~ms}, 30 \mathrm{~ms}, 40 \mathrm{~ms}$, etc. When other nodes receive synchronization messages from synchronization nodes, they empty their own counters so that all nodes synchronize once every 300 milliseconds. Other nodes use messages sent by synchronous nodes as the benchmark to send messages sequentially, which can avoid the problem of collision between multiple nodes at sending time, avoid bus competition, and reduce the possibility of message delay. At last, the vehicle state is calculated by the proposed algorithm in this paper. The whole simulation scheme based on HIL can be depicted as Figure 6. The values of the parameters for simulation are expressed in Table $1[19,30]$.

Two kinds of simulation tests are adopted to validate the estimation method. The first one is double-lane change 


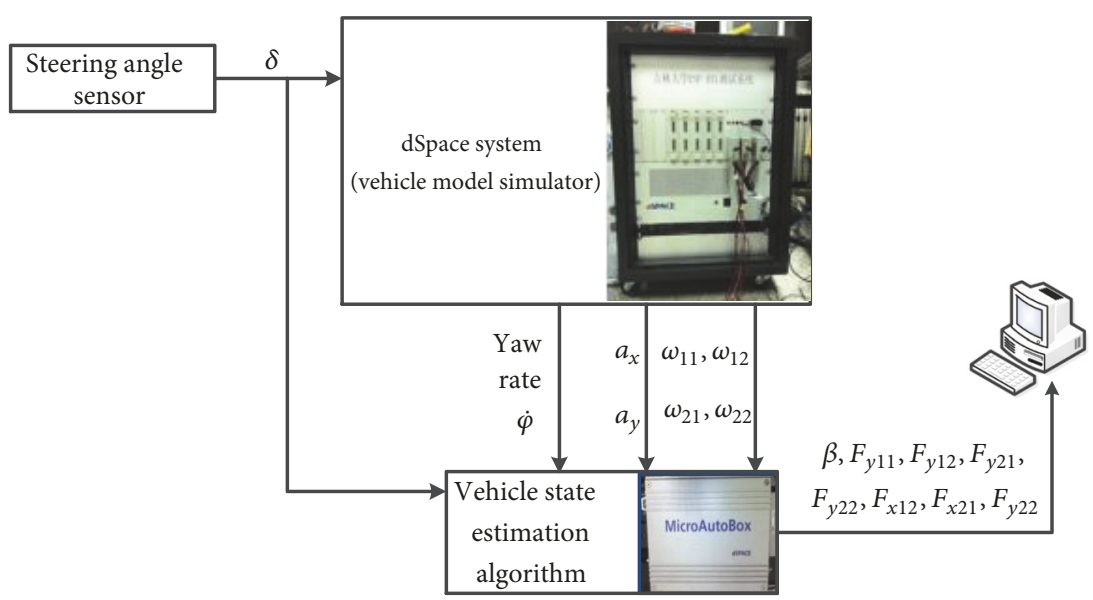

Figure 6: The simulation scheme based on HIL.



Steering angle

(a) Steer angle of steering wheel

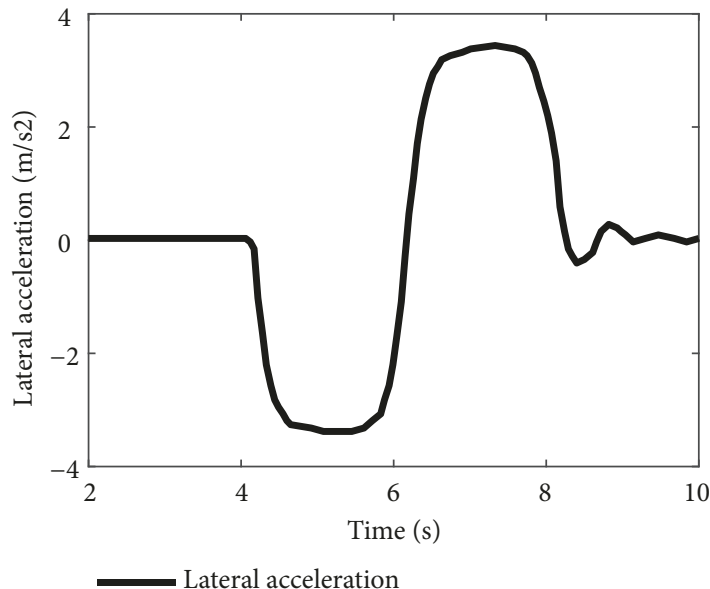

(b) The lateral acceleration of vehicle

Figure 7

TABLE 1: Parameters for simulation.

\begin{tabular}{lccc}
\hline Symbol & Value & Unit & Description \\
\hline$L_{f}$ & 1.4 & $\mathrm{~m}$ & Distance c.g. to front axle \\
$L_{r}$ & 1.4 & $\mathrm{~m}$ & Distance c.g. to rear axle \\
$C_{y f}$ & 110000 & $\mathrm{~N} / \mathrm{rad}$ & Front cornering stiffness \\
$C_{y r}$ & 95000 & $\mathrm{~N} / \mathrm{rad}$ & Rear cornering stiffness \\
$I_{z}$ & 3500 & $\mathrm{Kg} / \mathrm{m}^{2}$ & $\mathrm{M}$ \\
$B_{f}$ & 1.5 & $\mathrm{Kg}$ & Yaw moment of inertia \\
$m$ & 2000 & $\mathrm{Kg} / \mathrm{m}^{2}$ & Track width \\
$J_{w}$ & 1.3 & $\mathrm{M}$ & Vehicle mass \\
$\mathrm{R}$ & 0.28 & & Wheel inertia \\
\hline
\end{tabular}

(DLC) maneuvers on banked 5\% road to validate the method of lateral acceleration correction proposed in Section 4. The second one is DLC maneuvers on flat level road. And the simulation results of estimation method proposed in this paper are compared with the estimation based on CKF to discuss the performance of both methods.
5.1. Simulation Results of the DLC Manoeuver on Banked 5\% Road (Steering Angle Is 55 Degrees at $71 \mathrm{~km} / \mathrm{h}$ ). Figures 7(a) and 7(b) show the steering angle, lateral acceleration during DLC test on banked 5\% road. It is because of the existence of bank angle that the lateral acceleration is influenced. Figure 8 shows the simulation result of the estimated sideslip 


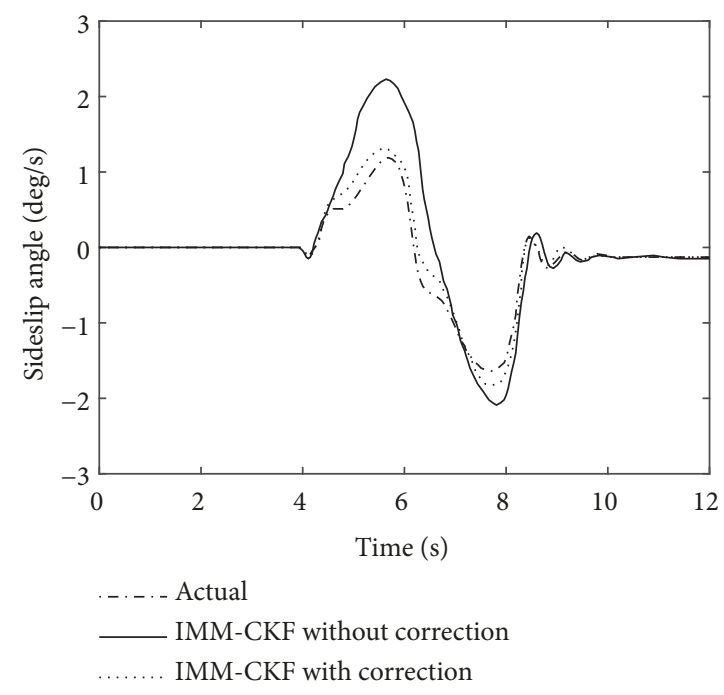

FIGURE 8: The estimated sideslip angle on banked 5\% road.

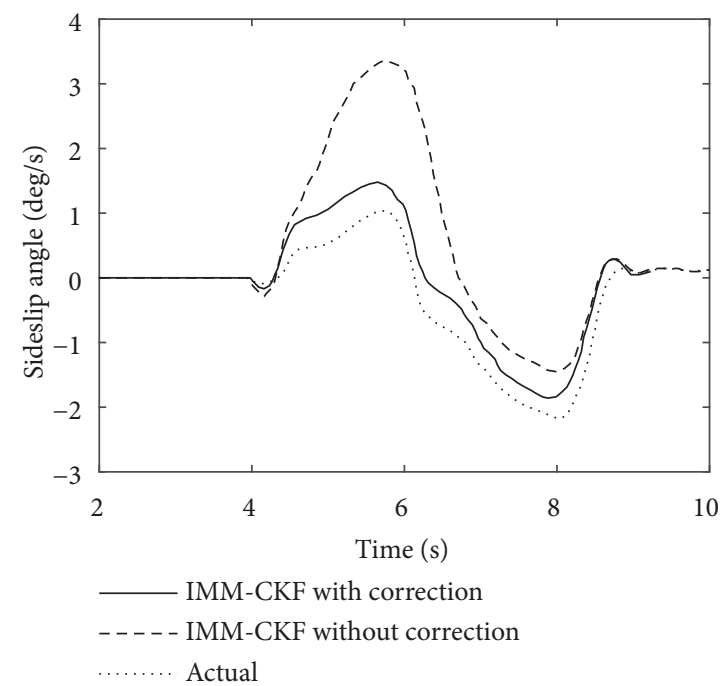

FIGURE 9: The estimated sideslip angle on banked $10 \%$ road.

angle on banked 5\% road. Seen from Figure 8, the sideslip angle estimated by IMM-CKF without the lateral acceleration correction deviates from the real one largely. In contrast, the value of sideslip angle estimated by IMM-CKF with lateral acceleration correction can predict more accurate value of sideslip angle as described in Figure 8. Thus the proposed IMM-CKF with lateral acceleration correction has robustness on the banked road.

Figure 9 shows the simulation results of the estimation method of the sideslip angle on banked $10 \%$. It can be seen from the curve that the error of the estimated sideslip angle becomes large for the reason of the increase in error of lateral acceleration.

5.2. Simulation Results of the DLC Manoeuver on Flat Level Road (Steering Angle Is 55 Degrees at $71 \mathrm{~km} / \mathrm{h}$ ). In this section, as shown in Figure 10, two kinds of simulation tests under high adhesion coefficient $(\mu=0.8)$ are adopted to compare the performance among the proposed estimator (IMMCKF), cubature Kalman filter (CKF), unscented Kalman filter (UKF), and extended Kalman filter (EKF). The simulation results, which include the estimated sideslip angle and the estimated tire-road force, are described in Figures 11-13. Figure 12 shows the simulation results of sideslip angle. The values estimated by other filter methods have more error than the value estimated by IMM-CKF. The same phenomenon can be observed in Figure 13. The IMM-CKF algorithm shows more accuracy than other methods. There is a small difference between the actual value and the value estimated by IMMCKF, which maybe neglects the effect of the suspension model.

As shown in Figure 12, during the time intervals (5-6s and $7-8 \mathrm{~s})$, the estimated sideslip and tire force are not consistent with the true value. The error is due to longitudinal load 


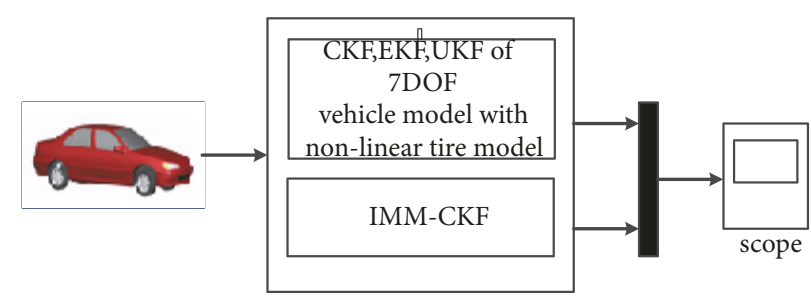

Figure 10: The simulation model for the sideslip angle estimation.

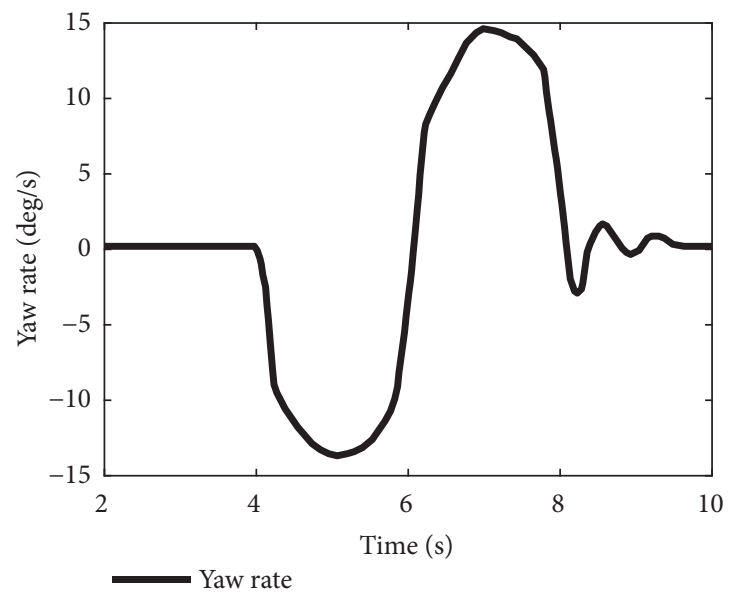

(a) The yaw rate of vehicle

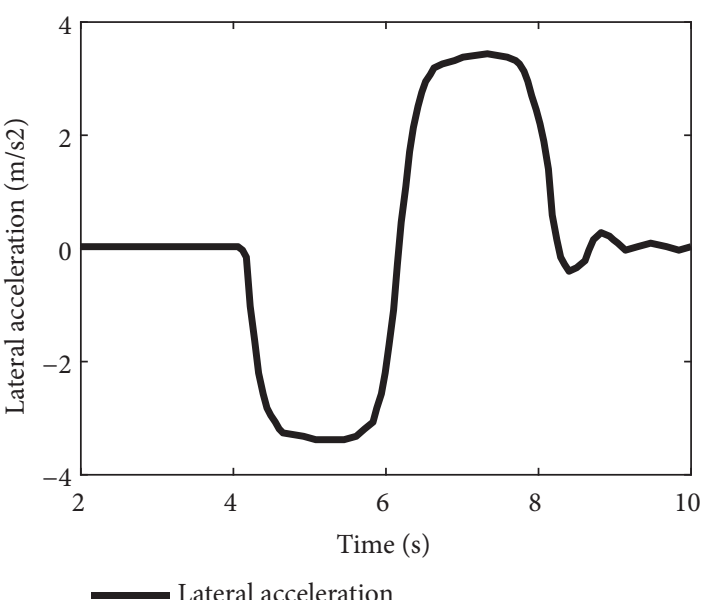

(b) The lateral acceleration of vehicle

Figure 11

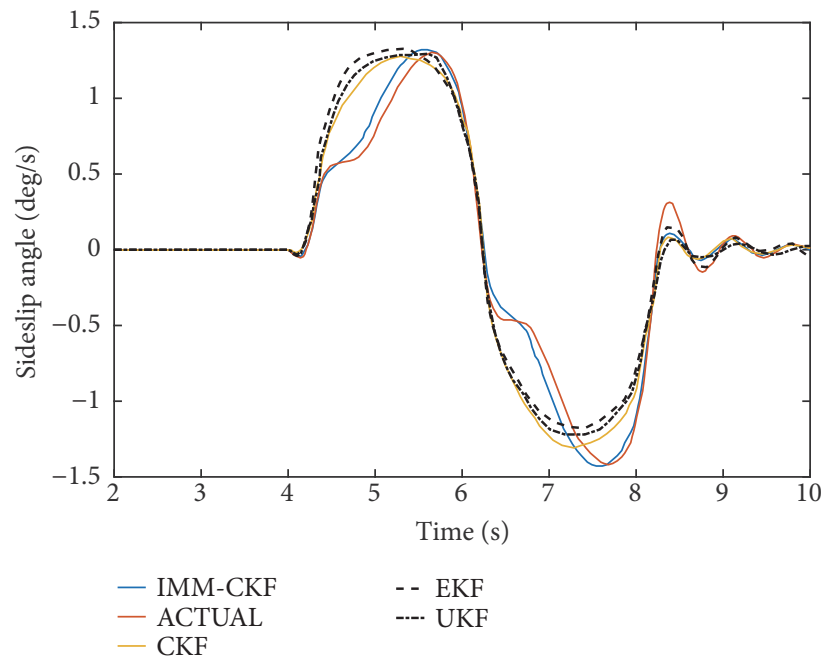

FIGURE 12: The estimated sideslip angle on flat level road.

transfer. With the increase of vehicle mass, the error increases gradually.

5.3. Simulation Results of the DLC Manoeuver on Banked $10 \%$ Road. In order to evaluate the correction of cornering stiffness, the steering input of DLC manoeuver on banked $10 \%$ road is generated. The simulation is done on ice road (road friction $\mu=0.3$ ), and the vehicle velocity is $60 \mathrm{~km} / \mathrm{h}$.
The simulation results with and without the correction of cornering stiffness are presented in Figure 14. The change of cornering stiffness is due to the drastic lateral load transfer, which immediately leads to the increase of the sideslip angle. As such, the estimation result with correction of cornering stiffness shows more robust performance, especially in presence of large sideslip angle regime, compared with the simulation result in the absence of correction about cornering 


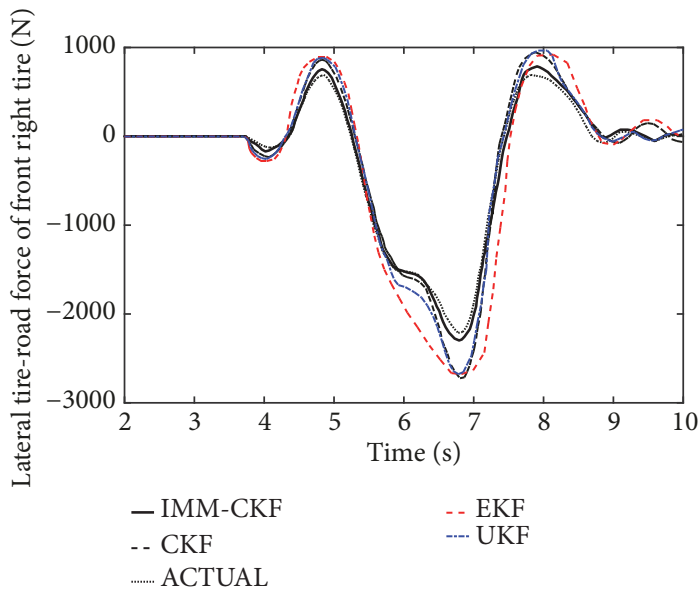

(a) Front right lateral tire force

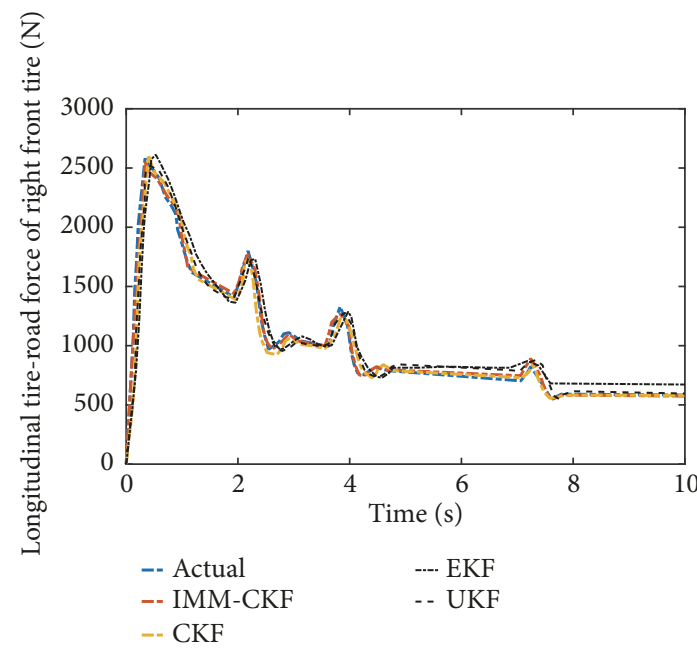

(c) Front right longitudinal tire force

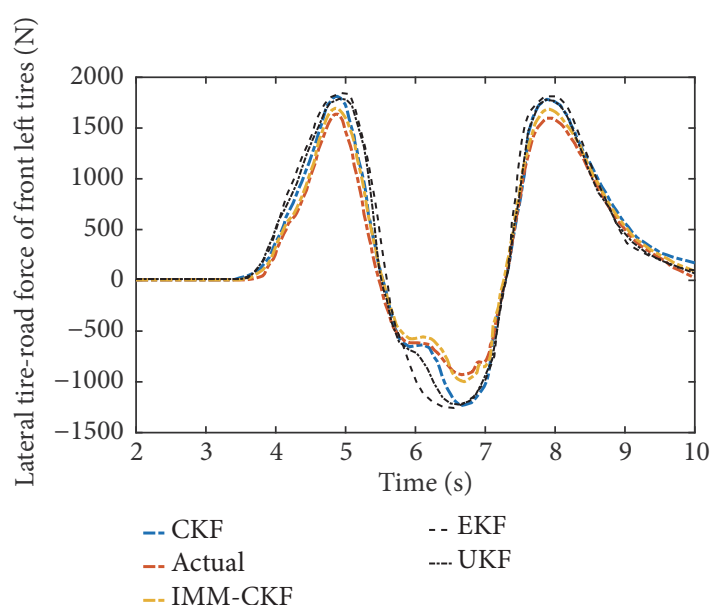

(b) Front left lateral tire force

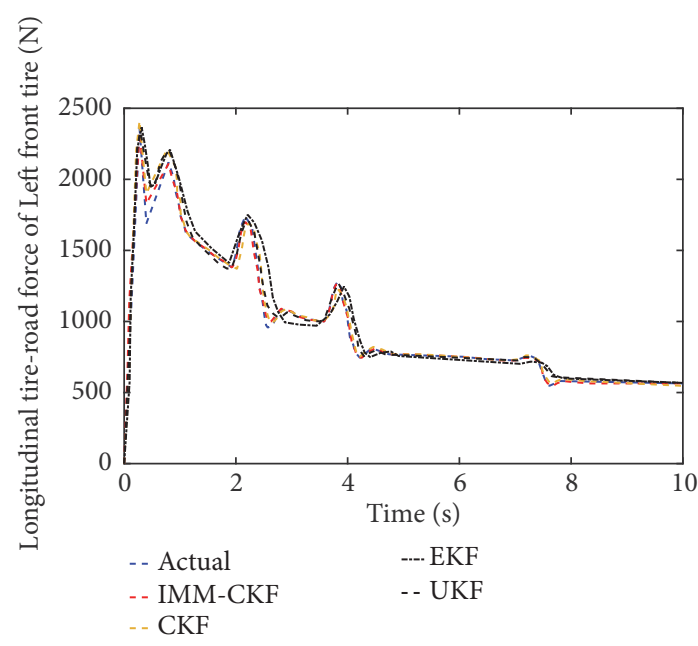

(d) Front left longitudinal tire force

FIGURE 13

stiffness. Such an obvious difference in the performance is observed clearly in the period between $8.5 \mathrm{~s}$ and $9 \mathrm{~s}$ in Figure 14(a). The result of correction is presented in Figures 14(b) and 14(c).

\section{Conclusions}

(1) For the sake of the various driving conditions, two vehicle models were built for estimation. The 7degree-of-freedom (7 DOF) vehicle model with linear tire model was built for normal driving condition, and the other is 7DOF vehicle model with nonlinear Dugoff tire model for the extreme driving condition. Two models were switched by IMM-CKF to match the different driving condition.

(2) To eliminate the estimation error caused by lateral acceleration sensor in case of vehicle driving on the slope road, the lateral acceleration correction for sideslip angle estimation is considered. The overall results from HIL verify that the proposed method can realize accurate estimation about vehicle state parameters in a wide range of road conditions. Meanwhile, the method is only applied on the mild banked road, and the application of the proposed approach under higher banking angle road would be concerned in the future research.

\section{Data Availability}

The data used to support the findings of this study are available from the corresponding author upon request.

\section{Conflicts of Interest}

The authors declare that there are no conflicts of interest regarding the publication of this paper.

\section{Acknowledgments}

This work is supported by Henan Science and Technology Project (192102210063; 182102210034). 


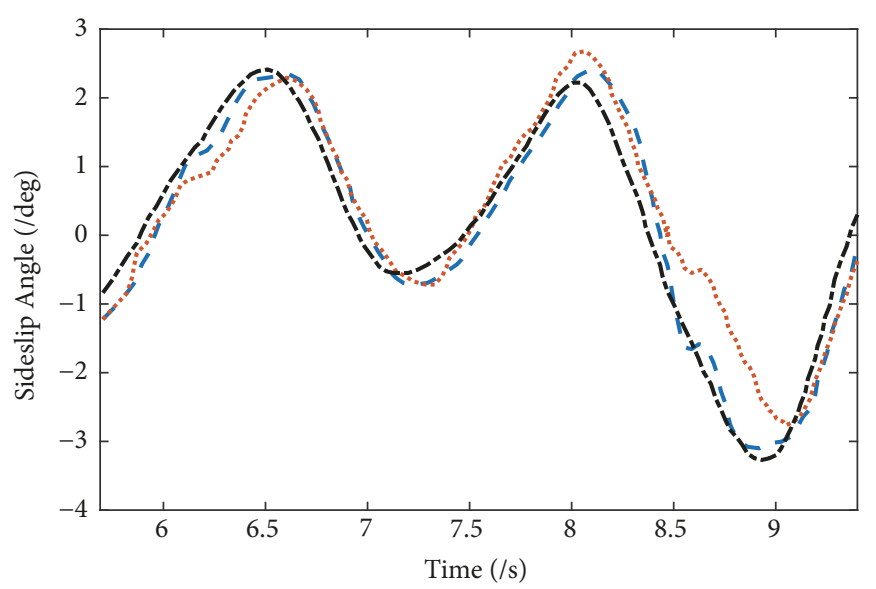

- estimated with correction

..... estimated without correction -- actual

(a) Estimated sideslip angle with and without cornering stiffness correction



(b) Front cornering stiffness



(c) Rear cornering stiffness

Figure 14

\section{References}

[1] M. Milanese, C. Novara, and I. Gerlero, "Robust estimation of vehicle sideslip angle from variables measured by ESC system," Internationales Stuttgarter Symposium, pp. 1063-1076, 2015.

[2] X. Li, X. Song, and C. Chan, "Reliable vehicle sideslip angle fusion estimation using low-cost sensors," Measurement, vol. 51, no. 1, pp. 241-258, 2014.

[3] H. Zhang, X. Huang, J. Wang, and H. R. Karimi, "Robust energy-to-peak sideslip angle estimation with applications to ground vehicles," Mechatronics, vol. 30, no. 1, pp. 338-347, 2015.

[4] B. L. Boada, M. J. L. Boada, and V. Diaz, "Vehicle sideslip angle measurement based on sensor data fusion using an integrated ANFIS and an Unscented Kalman Filter algorithm," Mechanical Systems and Signal Processing, vol. 72, no. 3, pp. 723-739, 2016.

[5] N. Ding and S. Taheri, "Application of recursive least square algorithm on estimation of vehicle sideslip angle and road friction," Mathematical Problems in Engineering, vol. 68, no. 6, pp. 1-18, 2010.
[6] C. Song, F. Xiao, S. Song, S. Li, and J. Li, "Design of a novel nonlinear observer to estimate sideslip angle and tire forces for distributed electric vehicle," Mathematical Problems in Engineering, vol. 215, no. 1, pp. 1-11, 2015.

[7] Z. Changzhu, C. Qijun, and Q. Jianbin, "Robust filtering for vehicle sideslip angle estimation with sampled-data measurements," Transactions of the Institute of Measurement and Control, vol. 73, no. 1, pp. 1-12, 2016.

[8] F. Cheli, E. Sabbioni, M. Pesce, and S. Melzi, "A methodology for vehicle sideslip angle identification: comparison with experimental data," Vehicle System Dynamics, vol. 45, no. 6, pp. 549563, 2007.

[9] P. J. T. Venhovens and K. Naab, "Vehicle dynamics estimation using Kalman filters," Vehicle System Dynamics, vol. 32, no. 2-3, pp. 171-184, 1999.

[10] G. Baffet, A. Charara, and D. Lechner, "Estimation of vehicle sideslip, tire force and wheel cornering stiffness," Control Engineering Practice, vol. 17, no. 11, pp. 1255-1264, 2009. 
[11] J. Stéphant, A. Charara, and D. Meizel, "Evaluation of a sliding mode observer for vehicle sideslip angle," Control Engineering Practice, vol. 15, no. 7, pp. 803-812, 2007.

[12] L. Li, G. Jia, X. Ran, J. Song, and K. Wu, "A variable structure extended Kalman filter for vehicle sideslip angle estimation on a low friction road," Vehicle System Dynamics, vol. 52, no. 2, pp. 280-308, 2014.

[13] Y. Chen, Y. Ji, and K. Guo, "A reduced-order nonlinear sliding mode observer for vehicle slip angle and tyre forces," Vehicle System Dynamics, vol. 52, no. 12, pp. 1716-1728, 2014.

[14] H. F. Grip, L. Imsland, T. A. Johansen, T. I. Fossen, J. C. Kalkkuhl, and A. Suissa, "Nonlinear vehicle side-slip estimation with friction adaptation," Automatica, vol. 44, no. 3, pp. 611-622, 2008.

[15] Y. F. Lian, Y. Zhao, L. L. Hu, and Y. T. Tian, "Cornering stiffness and sideslip angle estimation based on simplified lateral dynamic models for four-in-wheel-motor-driven electric vehicles with lateral tire force information," International Journal of Automotive Technology, vol. 16, no. 4, pp. 669-683, 2015.

[16] B. L. Boada, M. J. L. Boada, A. Gauchía, E. Olmeda, and V. Díaz, "Sideslip angle estimator based on ANFIS for vehicle handling and stability," Journal of Mechanical Science and Technology, vol. 29, no. 4, pp. 1473-1481, 2015.

[17] W. Liu, H. He, and F. Sun, "Vehicle state estimation based on minimum model error criterion combining with extended kalman filter," Journal of The Franklin Institute, vol. 353, no. 4, pp. 834-856, 2016.

[18] M. Dawood, C. Cappelle, M. E. El Najjar, M. Khalil, and D. Pomorski, "Vehicle geo-localization based on IMM-UKF data fusion using a GPS receiver, a video camera and a $3 \mathrm{D}$ city model," in Proceedings of the 2011 IEEE Intelligent Vehicles Symposium, IV'11, pp. 510-515, Germany, June 2011.

[19] X. Gao, Z. Yu, J. Neubeck, and J. Wiedemann, "Sideslip angle estimation based on input-output linearisation with tire-road friction adaptation," Vehicle System Dynamics, vol. 48, no. 2, pp. 217-234, 2010.

[20] H. Dugoff, P. S. Fancher, and L. Segel, "An analysis of tire properties and their influence on vehicle dynamic performance," $S A E$ paper, Article ID 700377, 1970.

[21] J.-F. Liao and B.-S. Chen, "Robust mobile location estimator with NLOS mitigation using interacting multiple model algorithm," IEEE Transactions on Wireless Communications, vol. 5, no. 11, pp. 3002-3006, 2006.

[22] S.-L. Koo and H.-S. Tan, "Tire dynamic deflection and its impact on vehicle longitudinal dynamics and control," IEEE/ASME Transactions on Mechatronics, vol. 12, no. 6, pp. 623-631, 2007.

[23] H. Zhang, Y. Shi, and J. Wang, "Observer-based tracking controller design for networked predictive control systems with uncertain Markov delays," International Journal of Control, vol. 86, no. 10, pp. 1824-1836, 2013.

[24] K. Jo, K. Chu, and M. Sunwoo, "Interacting multiple modelfilter-based sensor fusion of GPS with in-vehicle sensors for real-time vehicle positioning," IEEE Transactions on Intelligent Transportation Systems, vol. 13, no. 1, pp. 329-343, 2012.

[25] S. S. Blackman and R. Popoli, Design and Analysis of Modern Tracking Systems, Artech House, Noorwood, Mass, USA, 1999.

[26] Y. Shi, H. Zhang, and J. Wang, "On energy-to-peakfiltering for nonuniformly sampled nonlinear systems: a Markovian jump system approach," IEEE Transactions on Fuzzy Systems, vol. 22, no. 1, pp. 212-222, 2014.
[27] Y. Fukada, "Slip-angle estimation for vehicle stability control," Vehicle System Dynamics, vol. 32, no. 4, pp. 375-388, 1999.

[28] H. B. Pacejka, Tyre and Vehicle Dynamics, Butterworth Heinemann, London, UK, 2002.

[29] “VeDyna User’s Guide [G]," 1997.

[30] A. Nishio, K. Tozu, H. Yamaguchi, K. Asano, and Y. Amano, "Development of vehicle stability control system based on vehicle sideslip angle estimation," SAE Technical Papers, Article ID 010137, 2001. 


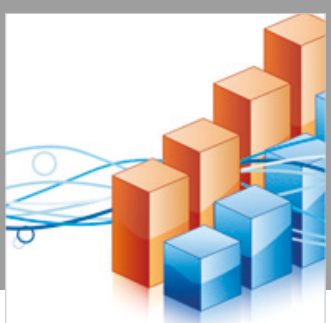

Advances in

Operations Research

\section{-n-m}
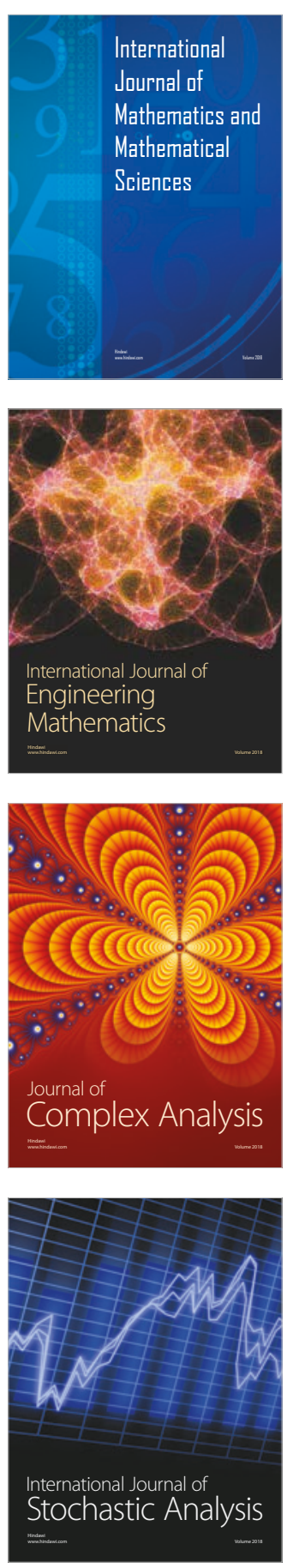


Journal of

Applied Mathematics


Submit your manuscripts at

www.hindawi.com

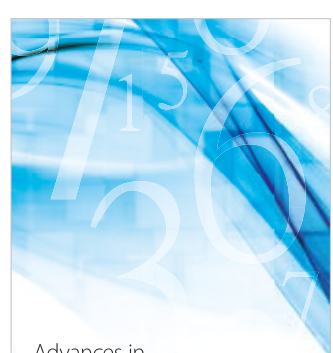

Advances in
Numerical Analysis
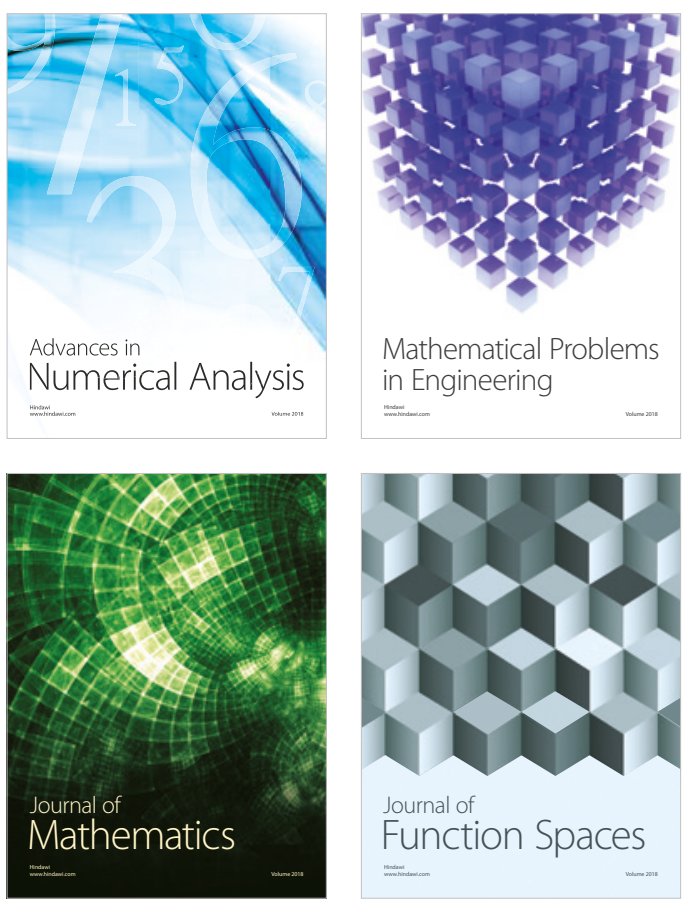

Mathematical Problems in Engineering

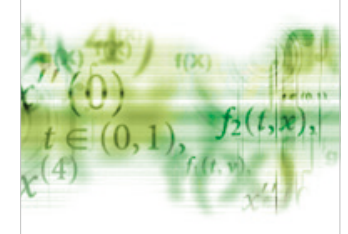

International Journal of

Differential Equations

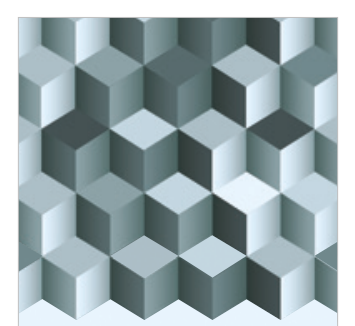

Journal of

Function Spaces

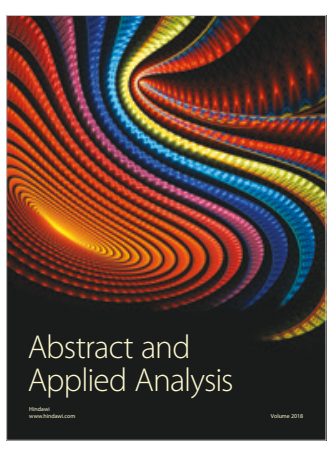

The Scientific

World Journal



Journal of

Probability and Statistics
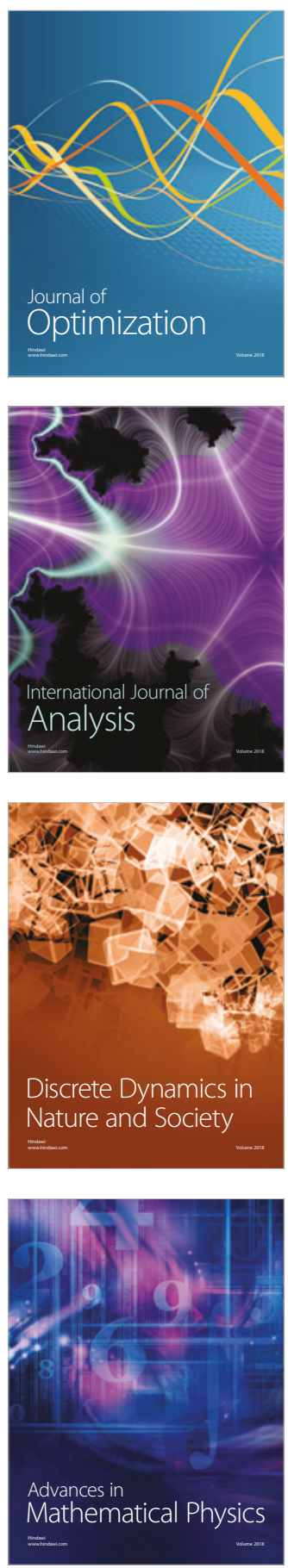